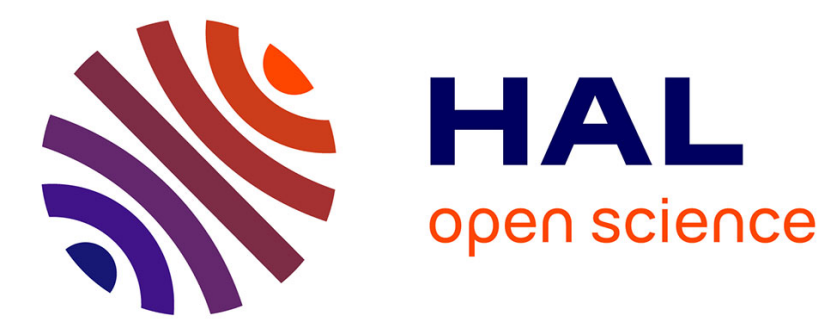

\title{
A fuzzy approach to analogical reasoning
}

\author{
Bernadette Bouchon-Meunier, Llorenç Valverde
}

\section{To cite this version:}

Bernadette Bouchon-Meunier, Llorenç Valverde. A fuzzy approach to analogical reasoning. Soft Computing, 1999, 3 (3), pp.141-147. 10.1007/s005000050062 . hal-01302874

\section{HAL Id: hal-01302874 https://hal.science/hal-01302874}

Submitted on 15 Apr 2016

HAL is a multi-disciplinary open access archive for the deposit and dissemination of scientific research documents, whether they are published or not. The documents may come from teaching and research institutions in France or abroad, or from public or private research centers.
L'archive ouverte pluridisciplinaire HAL, est destinée au dépôt et à la diffusion de documents scientifiques de niveau recherche, publiés ou non, émanant des établissements d'enseignement et de recherche français ou étrangers, des laboratoires publics ou privés. 


\title{
A fuzzy approach to analogical reasoning
}

\author{
Bernadette Bouchon-Meunier, Llorenç Valverde \\ * LIP6, UPMC, Case 169 \\ 4 place Jussieu \\ 75252 Paris Cédex 05, France \\ bouchon@poleia.lip6.fr \\ 'Dept. de Matematiques i Informatica \\ Universitat de les Iles Balears, C. de Valldemossa \\ 07071 Palma, Spain \\ dmilvg0@ps.uib.es
}

\begin{abstract}
We address the problem of the representation of resemblances involved in analogical reasoning. We use fuzzy relations to compare situations. We provide constructive methods to adapt the solution of an already solved situation to a similar new situation according to the degree of resemblance between these two situations. We give a general definition of analogical scheme which can be considered from a more or less constrained point of view.
\end{abstract}

\section{Introduction}

Analogy is a natural means of drawing a conclusion in human reasoning. Analogy is common in problem solving, such as mathematical problem solving or problems regarding the way to use a new device, where knowledge of the domain and already solved problems are used together to help solving a new problem. Analogy is also used in classification, where we use already classified objects of the same kind to decide which class we must assign to a new object, for instance classification of handwritten characters or image processing elements. Two approaches of natural analogy exist in literature. The first one regards analogy as a way to manage a new piece of information $\mathrm{A}^{\prime}$ on the basis of already processed pieces of information $\left\{\mathrm{A}_{\mathrm{i}} / \mathrm{i} \in \mathrm{I}\right\}$, and basic knowledge on the domain which is concerned; we look for the already processed piece of information $\mathrm{A}_{\mathrm{i}_{\mathrm{o}}}$ which resembles most the new one $\mathrm{A}^{\prime}$ and we construct a solution to manage $A^{\prime}$ which resembles or is identical to the existing solution $B_{i_{o}}$ of $A_{i_{0}}$. The second approach considers two domains $\Omega_{1}$ and $\Omega_{2}$ (for instance electricity and hydrology) and proposes to solve a problem $\mathrm{A}^{\prime}$ in $\Omega_{2}$ on the basis of its resemblance with an already solved problem $\mathrm{A}_{\mathrm{i}_{\mathrm{o}}}$ in $\Omega_{1}$; general knowledge is given on $\Omega_{1}$ and $\Omega_{2}$, and resemblances are established between their components. In both cases, the concept of resemblance is fundamental. Then, once $A_{i_{o}}$ has been identified for a given $A^{\prime}$, it is not obvious to construct the solution of $A^{\prime}$ from the solution $B_{i_{o}}$ of $A_{i_{0}}$. In the first approach, the solution of $\mathrm{A}_{\mathrm{i}_{\mathrm{o}}}$ can be preserved to solve $\mathrm{A}^{\prime}$, but it must sometimes be 
modified since $\left[\mathrm{A}^{\prime}\right]$ is not identical but only similar to $\mathrm{A}_{\mathrm{i}_{0}}$. In the second approach, it is clear that the solution of $A_{i_{0}}$ must be adapted to domain $\Omega_{2}$.

In human reasoning, a resemblance is identified globally between pieces of information or situations and intensive work has been done in psychology [Richard 95] to study the recognition of resemblance. Let us take the example of an analogical determination of the price of a house, according to several criteria, such as its size, its state, its location... When we have to assign a price to a house $\mathrm{H}$, we look for houses similar to $\mathrm{H}$ according to the criteria, and their prices are used to determine the price of H.

In artificial intelligence, analogy is also an explored domain, analogical reasoning is generally regarded from the second above-mentioned point of view, while case-based reasoning corresponds to the first one. In both approaches, the definition of resemblances is crucial and very often given in a prior way, but there exist very few studies on adapting the existing solution to the new piece of information.

Analogical reasoning has been formalized in a fuzzy set based approach in various directions. Approximate reasoning has been pointed out by L.A. Zadeh [Zadeh 79] as underlying the "remarkable human ability to ... make rational decisions in complex and/or uncertain environments", it has been initiated in fuzzy logic as a method of automatic reasoning as close as possible to human reasoning [Zadeh 83]. Then, it seems natural that it provides a convenient framework for the representation of analogy, which is at the root of most of human reasoning processes. Several kinds of connections between approximate reasoning and analogy have been explored [Baldwin 79], [Dubois, Prade 92], [Magrez, Smets 89], [Mukaidono et al. 90], [Smets 91], [Turksen, Lucas 91], [Turksen, Zhong 88]. We approach this problem through properties of the measures of similarity or the resemblances underlying the analogy.

In this paper, we give a general analogical scheme which can be made more specific in different ways to capture several aspects of analogy which exist in the literature or which can be analyzed.

\section{Analogical scheme}

We consider two variables $\mathrm{V}$ and $\mathrm{W}$ defined on universes $\mathrm{X}$ and $\mathrm{Y}$. Let us denote by $F(X)$ and $F(Y)$ respective sets of fuzzy sets of $X$ and $Y$, which are either the sets $[0,1]^{X}$ and $[0,1]^{\mathrm{Y}}$ of all fuzzy sets of $\mathrm{X}$ and $\mathrm{Y}$, or subsets of $[0,1]^{\mathrm{X}}$ and $[0,1]^{\mathrm{Y}}$. For instance, with the example of houses, $\mathrm{V}$ can be the size, the state, the location, $\mathrm{W}$ the price. 
Definition 1 [Bouchon-Meunier et al. 97] - For a given relation $\beta$ on $[0,1]^{\mathrm{X}} \times[0,1]^{\mathrm{Y}}$ and two relations $\mathrm{R}_{\mathrm{X}}$ on $[0,1]^{\mathrm{X}} \times[0,1]^{\mathrm{X}}$ and $\mathrm{R}_{\mathrm{Y}}$ on $[0,1]^{\mathrm{Y}} \times[0,1]^{\mathrm{Y}}$, an analogical scheme is a function:

$$
\Re_{\beta R_{X} R_{Y}}: F(X) \times F(Y) \times[0,1]^{X} \rightarrow[0,1]^{Y} \text { satisfying }
$$

$\forall \mathrm{A} \in \mathrm{F}(\mathrm{X})$ and $\forall \mathrm{B} \in \mathrm{F}(\mathrm{Y})$ such that $\mathrm{A} \beta \mathrm{B}, \forall \mathrm{A}^{\prime} \in[0,1]^{\mathrm{X}}$ such that $\mathrm{AR}_{\mathrm{X}} \mathrm{A}^{\prime}$

(AS1) $\mathrm{B}=\Re_{\beta R_{X^{R}}}(\mathrm{~A}, \mathrm{~B}, \mathrm{~A})$

$(\mathrm{AS} 2) \mathrm{B}^{\prime}=\mathfrak{R}_{\beta \mathrm{R}_{\mathrm{X}} \mathrm{R}_{\mathrm{Y}}}\left(\mathrm{A}, \mathrm{B}, \mathrm{A}^{\prime}\right)$ satisfies $\left(\mathrm{A}^{\prime} \beta \mathrm{B}^{\prime}\right.$ and $\left.\mathrm{BR}_{\mathrm{Y}} \mathrm{B}^{\prime}\right)$

We can interprete this scheme as follows, as soon as $\beta, R_{X}$ and $R_{Y}$ are defined properly : if $A$ and $B$ are known to be linked by $\beta$, and if $A^{\prime}$ resembles $A$ through $R_{X}$, we are able to find $\mathrm{B}^{\prime}$ such that $\mathrm{A}^{\prime}$ and $\mathrm{B}^{\prime}$ are linked by $\beta$ and $\mathrm{B}^{\prime}$ resembles $\mathrm{B}$ through $\mathrm{R}_{\mathrm{Y}}$ (figure 1).

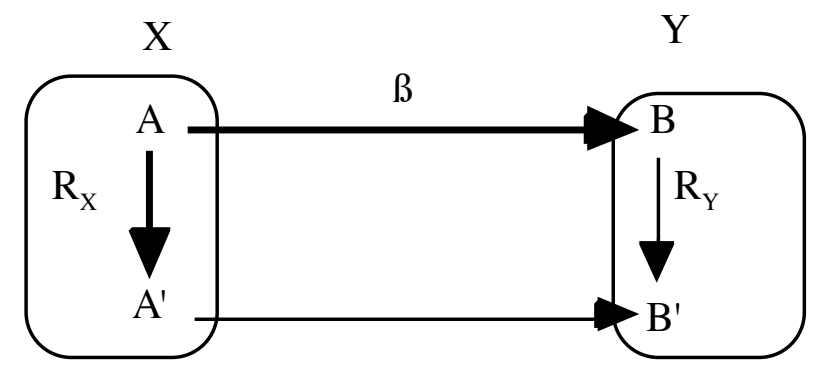

Figure 1 : Analogical scheme

Our purpose is to study proper definitions of $\beta, \mathrm{R}_{\mathrm{X}}$ and $\mathrm{R}_{\mathrm{Y}}$, so that an analogical scheme can be defined as a modelization of natural analogy, in the framework of fuzzy logic. In this paper, we use the same notation for a fuzzy set and for its membership function.

\section{Resemblance relations}

In order to focus on relations $\mathrm{R}_{\mathrm{X}}$ and $\mathrm{R}_{\mathrm{Y}}$ corresponding to the idea of resemblance or closeness at the root of an analogical scheme, we study a particular family of fuzzy relations on the set of fuzzy subsets of a given universe [Bouchon-Meunier 92], [Bouchon-Meunier, Valverde 92] defined through a triangular norm [Schweizer, Sklar 63].

\subsection{General definition of resemblance relations}

Definition 2 - A resemblance relation on $[0,1]^{\mathrm{X}}$ is defined as a fuzzy relation :

$$
r_{X}:[0,1]^{X} \times[0,1]^{X} \rightarrow[0,1]
$$

satisfying the following properties for every $\mathrm{A}, \mathrm{A}^{\prime}, \mathrm{A}^{\prime \prime}$ in $[0,1]^{\mathrm{X}}$ : 
(RR1) $\mathrm{T}\left(\mathrm{r}_{\mathrm{X}}\left(\mathrm{A}, \mathrm{A}^{\prime}\right), \mathrm{r}_{\mathrm{X}}\left(\mathrm{A}^{\prime}, \mathrm{A}^{\prime \prime}\right)\right) \leq \mathrm{r}_{\mathrm{X}}\left(\mathrm{A}, \mathrm{A}^{\prime \prime}\right) \quad$ (T-transitivity), where $\mathrm{T}$ stands for a continuous triangular norm.

$(\mathrm{RR} 2)$ if $\mathrm{A} \supseteq \mathrm{A}^{\prime}$ then $\mathrm{r}_{\mathrm{X}}\left(\mathrm{A}, \mathrm{A}^{\prime}\right)=1$ (containment)

We use the classical definition of the inclusion of fuzzy sets :

$\mathrm{A} \supseteq \mathrm{A}^{\prime}$ if and only if $\forall \mathrm{x} \in \mathrm{X} \quad \mathrm{A}(\mathrm{x}) \geq \mathrm{A}^{\prime}(\mathrm{x})$

Let us remark the following :

- Property (RR2) implies the reflexivity property :

(RR3) $r_{X}(A, A)=1$,

- We do not ask a resemblance relation to be symmetrical, since $\mathrm{A}$ and $\mathrm{A}^{\prime}$ do not have the same status, $\mathrm{A}$ serving as a reference, $\mathrm{A}^{\prime}$ being compared to $\mathrm{A}$.

- The T-transitivity is weaker than the min-transitivity (classical extension of transitivity of crisp relations to fuzzy ones), which means that a min-transitive fuzzy relation $r_{X}$ is also T-transitive, and the contrary is false. More precisely, for any threshold $\rho$ in $[0,1]$, if $r_{X}\left(A, A^{\prime}\right) \geq \rho$ and $r_{X}\left(A^{\prime}, A^{\prime \prime}\right) \geq \rho$, we only get $r_{X}\left(A, A^{\prime \prime}\right) \geq T(\rho, \rho)$ with $T(\rho, \rho) \leq \rho$.

- Properties (RR1) and (RR3) prove that a resemblance relation is a T-preorder and a symmetrical resemblance relation is a $\mathrm{T}$-indistinguability operator [Valverde 85]. If $\mathrm{T}=$ min, a resemblance relation is a reflexive fuzzy ordering [Zadeh 71] or a similarity relation if it is symmetrical. If $\mathrm{T}$ has an additive generator (stricly decreasing) $\varphi$ then $\mathrm{d}$ defined by

$$
\mathrm{d}\left(\mathrm{A}, \mathrm{A}^{\prime}\right)=\varphi\left(\mathrm{r}_{\mathrm{X}}\left(\mathrm{A}, \mathrm{A}^{\prime}\right)\right)
$$

has the properties of a pseudo-distance (non necessarily symmetrical) and it can be regarded as a "proximity" of $\mathrm{A}^{\prime}$ with regard to $\mathrm{A}$. Conversely, if $\mathrm{d}$ is a pseudo-distance on $[0,1]^{\mathrm{X}}$ and $\mathrm{f}$ a continuous strictly decreasing function from $[0,+\infty]$ into $[0,1]$, then

$$
r_{X}^{d}\left(A, A^{\prime}\right)=f\left(d\left(A, A^{\prime}\right)\right)
$$

is a resemblance relation on $[0,1]^{\mathrm{X}}, \mathrm{T}$-transitive for a $\mathrm{t}$-norm $\mathrm{T}$ with additive generator $\mathrm{f}$ [Valverde 85].

\subsection{Particular resemblance relations}

An example of resemblance relation on $[0,1]^{\mathrm{X}}$ is the following :

$$
\mathrm{r}_{\mathrm{X}}\left(\mathrm{A}, \mathrm{A}^{\prime}\right)=\inf _{\mathrm{x} \in \mathrm{X}} \mathrm{T}^{*}\left(\mathrm{~A}^{\prime}(\mathrm{x}) \mid \mathrm{A}(\mathrm{x})\right)
$$

with the quasi-inverse of $\mathrm{T}$ defined by $\mathrm{T}^{*}(\mathrm{u} / \mathrm{v})=\sup \{\mathrm{w} \in[0,1] / \mathrm{T}(\mathrm{u}, \mathrm{w}) \leq \mathrm{v}\}$

It is easy to prove that $r_{x}$ satisfies properties (RR1) and (RR2), because of the following properties satisfied by the quasi-inverse $T^{*}$ of any continuous t-norm $\mathrm{T}$ :

$-\mathrm{T}\left(\mathrm{T}^{*}(\mathrm{u} \mid \mathrm{v}), \mathrm{T}^{*}(\mathrm{v} \mid \mathrm{w})\right) \leq \mathrm{T}^{*}(\mathrm{u} \mid \mathrm{w})$ for any $\mathrm{u}, \mathrm{v}, \mathrm{w}$ in $[0,1]$. 
$-\mathrm{T}^{*}(\mathrm{u} \mid \mathrm{v})=1$ if and only if $\mathrm{u} \leq \mathrm{v}$.

For instance, with the Lukasiewicz triangular norm defined as

$$
\mathrm{T}(\mathrm{u}, \mathrm{v})=\max (\mathrm{u}+\mathrm{v}-1,0),
$$

with $\mathrm{T}^{*}(\mathrm{u} \mid \mathrm{v})=\min (1-\mathrm{u}+\mathrm{v}, 1)$ and $\varphi(\mathrm{u})=1-\mathrm{u}$, we have

$r_{X}\left(A, A^{\prime}\right)=\inf _{x \in X} \min \left(1-A^{\prime}(x)+A(x), 1\right)$,

associated with the pseudo-distance

$$
\mathrm{d}\left(\mathrm{A}, \mathrm{A}^{\prime}\right)=\sup _{\mathrm{x} \in \mathrm{X}} \max \left(\mathrm{A}^{\prime}(\mathrm{x})-\mathrm{A}(\mathrm{x}), 0\right) \text {. }
$$

The greatest the resemblance, the smallest the pseudo-distance.

For sake of simplicity, let us consider the example of houses characterized by their sizes, with $X$ the universe of positive real numbers. We suppose that a reference house is characterized by the description $\mathrm{A}=$ "around $120 \mathrm{~m}^{2}$ ", represented by the fuzzy set of $\mathrm{X}$, also denoted by $\mathrm{A}$ in figure 2 . Another house is characterized by the description $\mathrm{A}^{\prime}$ $=$ "around $135 \mathrm{~m}^{2}$ " represented by the corresponding fuzzy set of $\mathrm{X}$ with membership function given in figure 2 . Its resemblance with the reference house can be evaluated by $\mathrm{r}_{\mathrm{X}}\left(\mathrm{A}, \mathrm{A}^{\prime}\right)=0.5$.

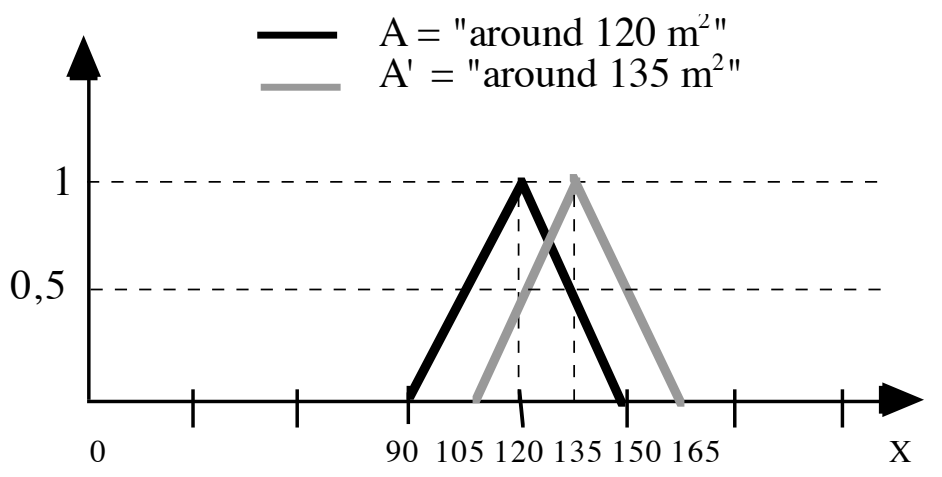

Figure 2 : Resemblance of fuzzy sets

\subsection{General form of resemblance relations}

The representation theorem [Valverde 85] for fuzzy binary relations $r_{x}$ on a given universe indicates that, if $r_{X}$ defined on $[0,1]^{X}$ satisfies (RR3), and it is particularly true if it satisfies (RR2), then $r_{X}$ satisfies (RR1) for a continuous triangular norm $T$ if and only if there exists a family $\left\{h_{k}, k \in K\right\}$ of fuzzy subsets of $[0,1]^{X}$ such that :

$$
r_{X}\left(A, A^{\prime}\right)=\inf _{k \in K} T^{*}\left(h_{k}\left(A^{\prime}\right) \mid h_{k}(A)\right)
$$

which generalizes the particular form of resemblance relations given in (3), corresponding to $K=X$ and the functions $h_{x}(A)=A(x)$ for any $x \in X$. For a fuzzy binary relation $r_{X}$ on $[0,1]^{X}$, formula (6) gives the general form of resemblance 
relations that are $\mathrm{T}$-transitive for the triangular norm $\mathrm{T}$ if and only if, for any $\mathrm{k} \in \mathrm{K}, \mathrm{h}_{\mathrm{k}}$ is an increasing function [Bouchon-Meunier, Valverde 93b], i.e.

$$
\text { if } \mathrm{A}^{\prime} \subseteq \mathrm{A} \text { then } \mathrm{h}_{\mathrm{k}}\left(\mathrm{A}^{\prime}\right) \leq \mathrm{h}_{\mathrm{k}}(\mathrm{A}) \text {. }
$$

\section{Analogical scheme based on the compositional rule of inference}

\subsection{Compositional rule of inference}

The compositional rule of inference corresponds to an extension of the modus ponens procedure to fuzzy logic, also called generalized modus ponens. Let us consider a set $\mathrm{E}$ of situations associated with crisp or fuzzy values of $\mathrm{V}$ and $\mathrm{W}$, which can be known or not. We are supposed to be given a base of rules $\left(\mathrm{L}_{\mathrm{j}}\right), \mathrm{j} \in \mathrm{J}$, of the form "if $\mathrm{V}$ is $\mathrm{A}_{\mathrm{j}}$ then $\mathrm{W}$ is $\mathrm{B}_{\mathrm{j}}{ }^{\text {", }}$, with normalized (with a maximum membership degree equal to 1 ) fuzzy sets $A_{j}$ of $X$ and $B_{j}$ of $Y$.

The compositional rule of inference corresponds to the utilization of one of these rules, for instance "if V is $A$ then $\mathrm{W}$ is $\mathrm{B}$ ", for a situation described by "V is $\mathrm{A}$ '", with an unknown value of $\mathrm{W}$. It yields a conclusion of the form " $\mathrm{W}$ is $\mathrm{B}^{\prime}$ ", , computed as :

$$
\forall y \in Y \quad B^{\prime}(y)=\sup _{x \in X} \mathrm{t}\left(\mathrm{A}^{\prime}(\mathrm{x}), \mathrm{I}(\mathrm{x}, \mathrm{y})\right),
$$

for an implication I defined on $\mathrm{X} \times \mathrm{Y}$ as

$$
\forall(\mathrm{x}, \mathrm{y}) \in \mathrm{X} \times \mathrm{Y} \quad \mathrm{I}(\mathrm{x}, \mathrm{y})=\Phi(\mathrm{A}(\mathrm{x}), \mathrm{B}(\mathrm{y})) \text {, with } \Phi:[0,1] \times[0,1] \rightarrow[0,1] \text {. }
$$

$\mathrm{I}$ is supposed to be identical with the implication in classical logic if A and B are not fuzzy, and the generalized modus ponens operator $\mathrm{t}$ is chosen as a triangular norm such that $\mathrm{B}^{\prime}$ is identical with $\mathrm{B}$ as soon as $\mathrm{A}^{\prime}$ is identical with $\mathrm{A}$, which means that the compositional rule of inference is compatible with the classical modus ponens. We usually restrict ourselves to normalized fuzzy sets.

For instance, we can think of the rule "if the size is big, then the price is expensive", with a representation of "big" and "expensive" by means of fuzzy sets of the universe of positive real numbers. For a house characterized by "the size is around $120 \mathrm{~m}^{2}$ ", the compositional rule of inference provides a conclusion regarding its price.

There exist several classes of fuzzy implications and we consider the following definitions, among the most classical :

- the Kleene-Dienes implication defined as :

$$
\forall \mathrm{x} \in \mathrm{X} \quad \forall \mathrm{y} \in \mathrm{Y} \quad \mathrm{I}(\mathrm{x}, \mathrm{y})=\max (1-\mathrm{A}(\mathrm{x}), \mathrm{B}(\mathrm{y}))
$$

- the Lukasiewicz implication defined as :

$$
\forall(\mathrm{x}, \mathrm{y}) \in \mathrm{X} \times \mathrm{Y} \quad \mathrm{I}(\mathrm{x}, \mathrm{y})=\min (1-\mathrm{A}(\mathrm{x})+\mathrm{B}(\mathrm{y}), 1)
$$

With these fuzzy implications, we can use the Lukasiewicz triangular norm (4) as a generalized modus ponens operator $\mathrm{t}$. 


\subsection{General form of the analogical scheme}

In order to define an analogical scheme $\mathfrak{R}_{\beta \mathrm{R}_{\mathrm{X}} \mathrm{R}_{\mathrm{Y}}}$ corresponding to the compositional rule of inference, we consider $F(X)=\left\{A_{j}, j \in J\right\}$, and $F(Y)=\left\{B_{j}, j \in J\right\}$ respective finite subsets of $[0,1]^{\mathrm{X}}$ and $[0,1]^{\mathrm{Y}}$ obtained from the base of rules $\left(\mathrm{L}_{\mathrm{j}}\right), \mathrm{j} \in \mathrm{J}$.

The relation $\beta$ is defined by : $\mathrm{A} \beta \mathrm{B} \Leftrightarrow \mathrm{i}$ ) or ii) holds with :

i) $\exists$ a situation in $E$ associated with the value $A$ of $V$ and the value $B$ of $W$

ii) $\exists \mathrm{L}_{\mathrm{j}}$ such that $\mathrm{A}=\mathrm{A}_{\mathrm{j}}$ and $\mathrm{B}=\mathrm{B}_{\mathrm{j}}$

We look for two relations $R_{X}$ and $R_{Y}$ defined from resemblance relations. Then, we can introduce an analogical scheme in different ways.

\subsection{Heuristic definition of the analogical scheme}

Let us consider resemblance relations $r_{X}$ on $[0,1]^{X}$ defined in (3) and $r_{Y}$ on $[0,1]^{Y}$ of the same form :

$$
\mathrm{r}_{\mathrm{Y}}\left(\mathrm{B}, \mathrm{B}^{\prime}\right)=\inf _{\mathrm{y} \in \mathrm{Y}} \mathrm{T}^{*}\left(\mathrm{~B}^{\prime}(\mathrm{y}) \mid \mathrm{B}(\mathrm{y})\right)
$$

The simplest way to define an analogical scheme compatible with the compositional rule of inference is the following.

Let us start from a particular implication, for instance Kleene-Dienes implication (9). With the Lukasiewicz triangular norm as a generalized modus ponens operator and for the definition of $r_{X}$ and $r_{Y}$ in (3) and (11), yielding the form (5), it can be proven that, in particular cases of the resemblance between $\mathrm{A}^{\prime}$ and $\mathrm{A}$, we can describe immediatly the resemblance between $\mathrm{B}^{\prime}$ and $\mathrm{B}$. More precisely, we consider the four following situations :

(C1) $\mathrm{A}^{\prime}=\mathrm{m}(\mathrm{A})$ for a modifier $\mathrm{m}$ such as "rather", "about" [Bouchon-Meunier 88],

(C2) $A^{\prime}=$ "A with an uncertainty $1-\rho$ ", $\rho \in[0,1]$, which means that :

$$
\forall \mathrm{x} \in \mathrm{X} \quad \mathrm{A}^{\prime}(\mathrm{y})=\max (\mathrm{A}(\mathrm{y}), 1-\rho),
$$

(C3) $\mathrm{A}$ and $\mathrm{A}^{\prime}$ have the same support and $\mathrm{A}^{\prime}$ is less specific than $\mathrm{A}\left(\mathrm{A}^{\prime} \supseteq \mathrm{A}\right)$,

(C4) $B$ is precise and certain and corresponds for instance to the crisp description of a decision.

In the four situations, the conclusion $\mathrm{B}^{\prime}$ provided by the compositional rule of inference can be expressed as "B with an uncertainty $1-\rho$ ", with membership function

$\forall \mathrm{y} \in \mathrm{Y} \quad \mathrm{B}^{\prime}(\mathrm{y})=\max (\mathrm{B}(\mathrm{y}), 1-\rho)$

where $\rho$ depends on the parameter of the modifier [Bouchon-Meunier 90]. 
We further remark that if $r_{X}\left(A, A^{\prime}\right)=\rho$ then $r_{Y}\left(B, B^{\prime}\right)=\rho$. This means that, if $A^{\prime}$ resembles $A$ at the level $\rho$, then $B^{\prime}$ resembles $B$ at the same level.

In the case of Lukasiewicz implication (10), in situation (C1), the result $\mathrm{B}^{\prime}$ can be expressed as " $\mathrm{m}(\mathrm{B})$ with an uncertainty $1-\rho$ ", $\rho$ depending on the parameter defining $\mathrm{m}$, with again $r_{X}\left(A, A^{\prime}\right)=r_{Y}\left(B, B^{\prime}\right)=\rho$.

For cases (C2) to $(\mathrm{C} 4)$, the conclusions $\mathrm{B}^{\prime}$ are the same as those obtained with the Kleene-Dienes implication.

More generally, similar results can be proven for other classical implications [Bouchon-Meunier 93], such as implications defined through residuation of a given triangular norm $\mathrm{T}$ by

$$
\forall(x, y) \in X \times Y \quad I(x, y)=T^{*}(A(x) \mid B(y)) .
$$

From these four situations, we induce a heuristic construction of an analogical scheme. For any $\mathrm{A}^{\prime}, \mathrm{B}^{\prime}=\Re_{\beta \mathrm{R}_{\mathrm{X}} \mathrm{R}_{\mathrm{Y}}}\left(\mathrm{A}, \mathrm{B}, \mathrm{A}^{\prime}\right)$ is defined in such a way that, if $\mathrm{r}_{\mathrm{X}}\left(\mathrm{A}, \mathrm{A}^{\prime}\right)$ $=\rho$, then $r_{Y}\left(B, B^{\prime}\right)=\rho$. We define the analogical scheme $\Re_{\beta R_{X} R_{Y}}$ by means of relations $R_{X}$ and $R_{Y}$ obtained from $r_{X}$ and $r_{Y}$ as follows :

$$
\begin{aligned}
& \forall \mathrm{A}, \forall \mathrm{A}^{\prime} \in[0,1]^{\mathrm{X}} \quad \mathrm{AR}_{\mathrm{X}} \mathrm{A}^{\prime} \Leftrightarrow \mathrm{r}_{\mathrm{X}}\left(\mathrm{A}, \mathrm{A}^{\prime}\right)=\rho \\
& \forall \mathrm{B}, \quad \forall \mathrm{B}^{\prime} \in[0,1]^{\mathrm{Y}} \quad \mathrm{BR}_{\mathrm{Y}} \mathrm{B}^{\prime} \Leftrightarrow \mathrm{r}_{\mathrm{Y}}\left(\mathrm{B}, \mathrm{B}^{\prime}\right)=\rho .
\end{aligned}
$$

With the only constraint $r_{Y}\left(B, B^{\prime}\right)=\rho$, the membership function of $B^{\prime}$ is not uniquely determined. The choice of the shape of $\mathrm{B}^{\prime}$ depends on the kind of imperfection we want to manage. Obviously, if $\mathrm{A}^{\prime}$ is not exactly identical with $\mathrm{A}$, we have to adapt the information regarding $\mathrm{W}$.

- We can use an uncertainty, like in the case of the Kleene-Dienes implication and express $\mathrm{B}^{\prime}$ as "B with an uncertainty $1-\rho$ ". In this case, we define an analogical scheme by :

(F1) $\mathfrak{R}_{\beta R_{X} R_{Y}}\left(A, B, A^{\prime}\right)=B^{\prime} \Leftrightarrow B^{\prime}=\max (B, 1-\rho)$, with $\rho=r_{X}\left(A, A^{\prime}\right)$.

- We can also use an imprecision, for instance represented by means of a modifier and $\mathrm{B}^{\prime}$ is then expressed as $\mathrm{m}(\mathrm{B})$, for a modifier $\mathrm{m}$ of the form "rather", "about", with a parameter depending on $\rho$ [Bouchon-Meunier 87]. An analogical scheme is defined by

(F2) $\Re_{\beta R_{X} R_{Y}}\left(\mathrm{~A}, \mathrm{~B}, \mathrm{~A}^{\prime}\right)=\mathrm{B}^{\prime} \Leftrightarrow \mathrm{B}^{\prime}=\mathrm{m}(\mathrm{B})$ for a modifier $\mathrm{m}$ with a parameter linked to $\rho$ in such a way that $r_{Y}\left(B, B^{\prime}\right)=\rho$.

- We can also use a combination of uncertainty and imprecision, like in the case of Lukasiewicz implication and we have 
(F3) $\Re_{\beta R_{X} R_{Y}}\left(\mathrm{~A}, \mathrm{~B}, \mathrm{~A}^{\prime}\right)=\mathrm{B}^{\prime} \Leftrightarrow \mathrm{B}^{\prime}=\max (\mathrm{m}(\mathrm{B}), 1-\rho)$

In the example of the house, we can choose one of the three following types of conclusion:

- "the price is expensive, with an uncertainty $1-\rho$ " (form F1),

- "the price is rather expensive" with the modifier "rather" defined by parameter $\rho$, or "the price is about expensive" with the modifier "about" defined by parameter $1-\rho$, for instance (form F2).

- "the price is about expensive, with an uncertainty $1-\rho$ " (form F3) .
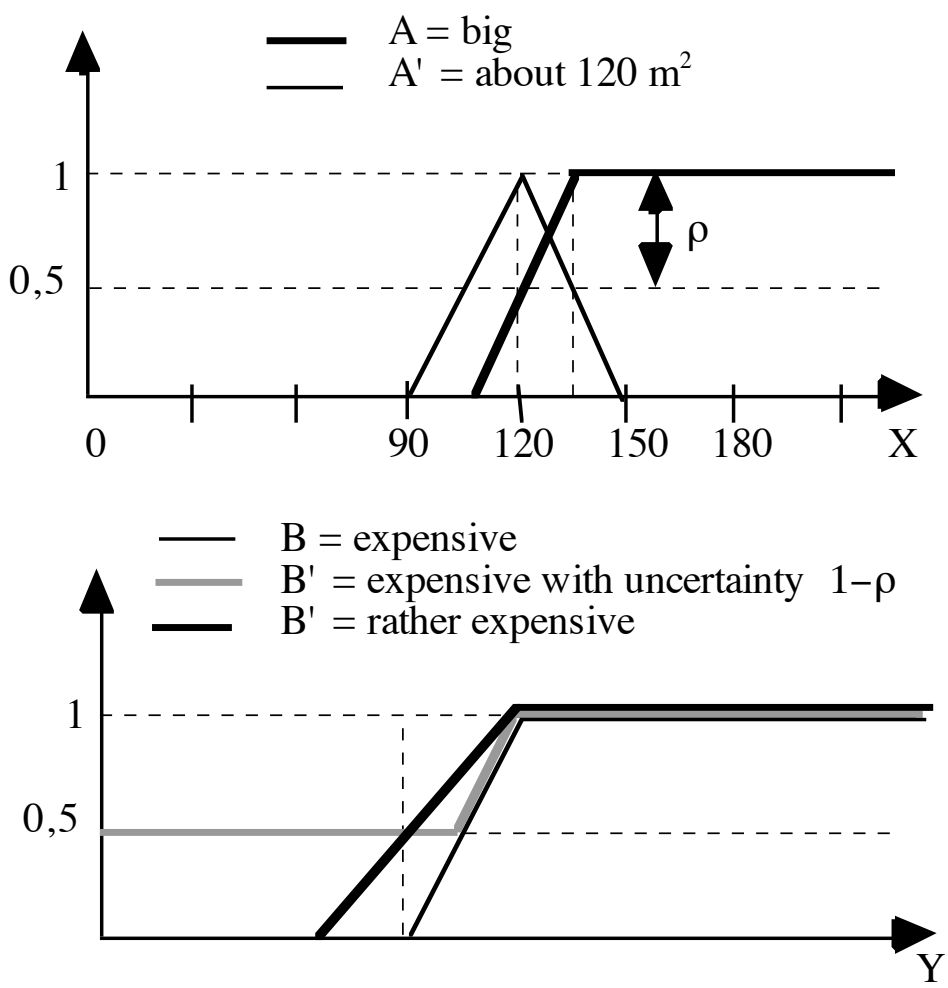

Figure 3 : Heuristic analogical scheme

We check that we get property $(\mathrm{AS} 1): \mathrm{B}=\Re_{\beta R_{X} R_{Y}}(\mathrm{~A}, \mathrm{~B}, \mathrm{~A})$ since $\mathrm{A}^{\prime}=\mathrm{A}$ implies $r_{x}(A, A)=1$ and then either $B^{\prime}=B$ with a null uncertainty, or $B^{\prime}=m(B)$ and the parameter defining $\mathrm{m}$ provides $\mathrm{m}(\mathrm{B})=\mathrm{B}$.

An automatic means of reasoning by analogy in the framework of fuzzy logic (more precisely in compatibility with the compositional rule of inference) is the following :

1.Choose a resemblance relation $r_{X}$ on $X$ and a resemblance relation $r_{Y}$ on $Y$, for instance of the form (5). 
2. For a given situation where the variable $\mathrm{V}$ is characterised by $\mathrm{A}^{\prime}$, look in the list $\left\{A_{j} / j \in J\right\}$ for a fuzzy set $A_{i_{o}}$ of $X$ such that $r_{X}\left(A_{i_{o}}, A^{\prime}\right)$ is maximum among all values $\mathrm{r}_{\mathrm{X}}\left(\mathrm{A}_{\mathrm{j}}, \mathrm{A}^{\prime}\right)$.

3. Construct $\mathrm{B}^{\prime}$ from the corresponding $\mathrm{B}_{\mathrm{i}_{\mathrm{o}}}$, as indicated above by choosing one of the three forms $(F 1),(F 2)$ or $(F 3)$, in such a way that $r_{Y}\left(B_{i_{0}}, B^{\prime}\right)=r_{X}\left(A_{i_{0}}, A^{\prime}\right)$.

We can summarize the underlying process as indicated in figure 4.

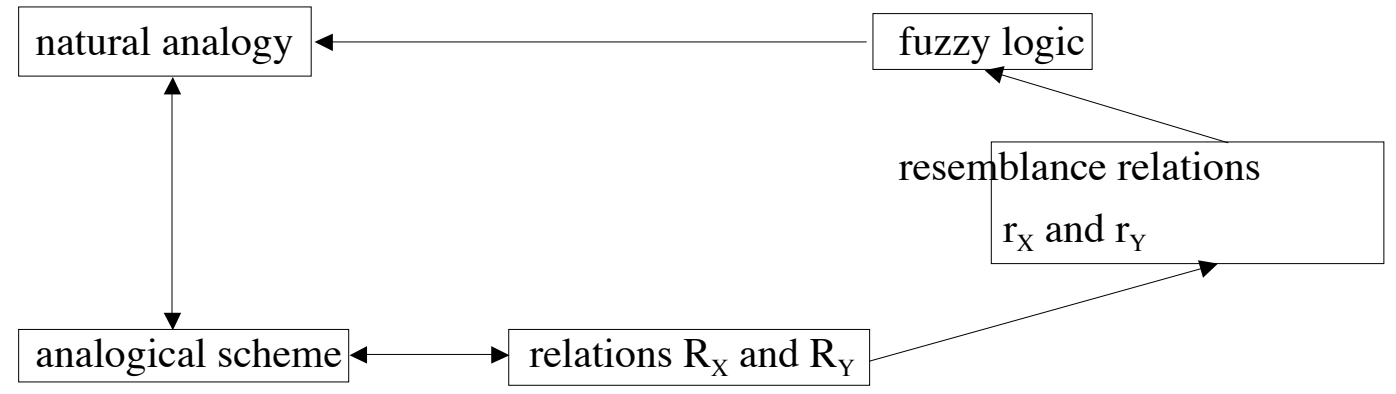

Figure 4 : Link between the main concepts

\subsection{Formal definition of an analogical scheme}

The automatic construction of $\mathrm{B}^{\prime}$ from $\mathrm{B}_{\mathrm{i}_{\mathrm{o}}}$ is based of results obtained through the compositional rule of inference on various but particular situations and we perform a kind of extrapolation of these results to any situation. In this section, we propose to justify this extrapolation by showing that the shapes of fuzzy sets obtained by one of the three forms $(\mathrm{F} 1),(\mathrm{F} 2)$ or $(\mathrm{F} 3)$ is determined by a more formal approach of an analogical scheme, based of the continuity of the reasoning process. This means that, if we know that $\mathrm{A}^{\prime}$ is close to $\mathrm{A}$, then we deduce that $\mathrm{B}^{\prime}$ is close to $\mathrm{B}$, with respect to resemblance relations $r_{X}$ on $[0,1]^{X}$ and $r_{Y}$ on $[0,1]^{\mathrm{Y}}$ satisfying (RR1) and (RR2).

For a given implication I, it is possible to introduce the following :

Definition 3 [Bouchon-Meunier, Valverde 1993a] - An $r_{X}-r_{Y}$ analogical reasoning function $\mathfrak{\Im}:[0,1]^{\mathrm{X}} \times[0,1]^{\mathrm{X} \times \mathrm{Y}} \rightarrow[0,1]^{\mathrm{Y}}$ satisfies :

$(\mathrm{AR} 1) \mathfrak{\Im}(\mathrm{A}, \mathrm{I}(\mathrm{A}, \mathrm{B}))=\mathrm{B}$

(AR2) with $\mathrm{B}^{\prime}=\Im(\mathrm{A}, \mathrm{I}(\mathrm{A}, \mathrm{B}))$, for any $\sigma \in[0,1]$ there exists $\rho_{\sigma}$ such that if $\min \left(r_{X}\left(A, A^{\prime}\right), r_{X}\left(A^{\prime}, A\right)\right) \geq \rho_{\sigma}$ then $\min \left(r_{Y}\left(B, B^{\prime}\right), r_{Y}\left(B^{\prime}, B\right)\right) \geq \sigma$.

If we introduce $\beta, F(X), F(Y)$ as in section 4.2, we can prove that an $r_{X}-r_{Y}$ analogical reasoning function is a particular analogical scheme. It is sufficient to choose $\Re_{\beta R_{X} R_{Y}}: F(X) \times F(Y) \times[0,1]^{X} \rightarrow[0,1]^{Y}$ such that :

$\forall \mathrm{A} \in \mathrm{F}(\mathrm{X}), \forall \mathrm{B} \in \mathrm{F}(\mathrm{Y}), \forall \mathrm{A}^{\prime} \in[0,1]^{\mathrm{X}} \Re_{\beta R_{\mathrm{X}} \mathrm{R}_{\mathrm{Y}}}\left(\mathrm{A}, \mathrm{B}, \mathrm{A}^{\prime}\right)=\Im\left(\mathrm{A}^{\prime}, \mathrm{I}(\mathrm{A}, \mathrm{B})\right)$. 
Property (AS1) is clearly satisfied by (AR1) and, if we define $R_{X}$ and $R_{Y}$, for a given threshold $\sigma$ and its corresponding value $\rho_{\sigma}$, in such a way that

$\forall \mathrm{A} \quad \forall \mathrm{A}^{\prime} \in[0,1]^{\mathrm{X}} \quad \mathrm{AR}_{\mathrm{X}} \mathrm{A}^{\prime} \Leftrightarrow \min \left(\mathrm{r}_{\mathrm{X}}\left(\mathrm{A}, \mathrm{A}^{\prime}\right), \mathrm{r}_{\mathrm{X}}\left(\mathrm{A}^{\prime}, \mathrm{A}\right)\right) \geq \rho_{\sigma}$

$\forall \mathrm{B} \forall \mathrm{B}^{\prime} \in[0,1]^{\mathrm{Y}} \quad \mathrm{BR}_{\mathrm{Y}} \mathrm{B}^{\prime} \Leftrightarrow \min \left(\mathrm{r}_{\mathrm{Y}}\left(\mathrm{B}, \mathrm{B}^{\prime}\right), \mathrm{r}_{\mathrm{Y}}\left(\mathrm{B}^{\prime}, \mathrm{B}\right)\right) \geq \sigma$, then $\Re_{\beta R S}$ satisfies (AS2) also and it is an analogical scheme.

\subsection{Justification of the heuristic approach by means of the formal definition of an analogical scheme}

Since $r_{X}$ and $r_{Y}$ are resemblance relations, they satisfy property (6), which gives upper and lower bounds of $\mathrm{B}^{\prime}$ for given $\mathrm{A}, \mathrm{B}, \mathrm{A}^{\prime}$ and a fixed threshold $\sigma$. The resemblance relation $r_{Y}$ is such that there exist a family of increasing functions $h_{k}, k \in K$, defined on $[0,1]^{Y}$ such that $r_{Y}\left(B, B^{\prime}\right)=\inf _{k \in K} T^{*}\left(h_{k}\left(B^{\prime}\right) \mid h_{k}(B)\right)$. Then, for any $A^{\prime}$ close to $A$ at the level $\rho_{\sigma}$ (or equivalently such that $\left.\min \left(r\left(A, A^{\prime}\right), r\left(A^{\prime}, A\right)\right) \geq \rho_{\sigma}\right)$, then $\inf _{k \in K} T^{*}\left(h_{k}\left(B^{\prime}\right) \mid h_{k}(B)\right) \geq \sigma$ and also $\inf _{k \in K} T^{*}\left(h_{k}(B) \mid h_{k}\left(B^{\prime}\right)\right) \geq \sigma$.

Consequently, for any $\mathrm{k} \in \mathrm{K}$, we have :

$\mathrm{T}^{*}\left(\mathrm{~h}_{\mathrm{k}}\left(\mathrm{B}^{\prime}\right) \mid \mathrm{h}_{\mathrm{k}}(\mathrm{B})\right) \geq \sigma$ and $\mathrm{T}^{*}\left(\mathrm{~h}_{\mathrm{k}}(\mathrm{B}) \mid \mathrm{h}_{\mathrm{k}}\left(\mathrm{B}^{\prime}\right)\right) \geq \sigma$.

Since any continuous triangular norm $\mathrm{T}$ satisfies for any $\mathrm{x}, \mathrm{y}, \mathrm{z}, \mathrm{T}^{*}(\mathrm{x} \mid \mathrm{y}) \geq \mathrm{z}$ if and only if $\mathrm{T}(\mathrm{z}, \mathrm{x}) \leq \mathrm{y}$, then the former conditions (15) are respectively equivalent to :

- $\mathrm{T}\left(\sigma, \mathrm{h}_{\mathrm{k}}\left(\mathrm{B}^{\prime}\right)\right) \leq \mathrm{h}_{\mathrm{k}}(\mathrm{B}) \quad$ or equivalently $\mathrm{T}\left(\mathrm{h}_{\mathrm{k}}\left(\mathrm{B}^{\prime}\right), \sigma\right) \leq \mathrm{h}_{\mathrm{k}}(\mathrm{B})$ and then $\mathrm{T}^{*}\left(\sigma \mid \mathrm{h}_{\mathrm{k}}(\mathrm{B}) \geq \mathrm{h}_{\mathrm{k}}\left(\mathrm{B}^{\prime}\right)\right.$,

- $\mathrm{T}\left(\sigma \mid \mathrm{h}_{\mathrm{k}}(\mathrm{B})\right) \leq \mathrm{h}_{\mathrm{k}}\left(\mathrm{B}^{\prime}\right)$,

which provides upper and lower bounds of $B^{\prime}$ because of the monotonicity of $h_{k}$.

In the particular case of resemblance relations defined by (3), we get $\mathrm{K}=\mathrm{X}$ and $\mathrm{h}_{\mathrm{x}}(\mathrm{A})=\mathrm{A}(\mathrm{x})$ for any $\mathrm{x} \in \mathrm{X}$. Thus, the upper and lower bounds of $\mathrm{B}^{\prime}$, respectively denoted by $\mathrm{B}_{\mathrm{U}}^{\prime}$ and $\mathrm{B}_{\mathrm{L}}^{\prime}$ are defined by :

$$
\forall \mathrm{y} \in \mathrm{Y} \quad \mathrm{T}^{*}(\sigma \mid \mathrm{B}(\mathrm{y}))=\mathrm{B}_{\mathrm{U}}^{\prime}(\mathrm{y})
$$

and $\forall \mathrm{y} \in \mathrm{Y} \quad \mathrm{T}(\sigma, \mathrm{B}(\mathrm{y}))=\mathrm{B}_{\mathrm{L}}^{\prime}(\mathrm{y})$.

The shapes of the upper and lower bounds of $\mathrm{B}^{\prime}$ justify in a formal way the heuristic possible definitions of $\mathrm{B}^{\prime}$ we gave in section 4.3. We must distinguish the cases of strict and non-strict triangular norms [Bouchon-Meunier, Valverde 93b].

\subsubsection{Case of strict triangular norms}

In this case, equation (16) yields a conclusion $\mathrm{B}_{\mathrm{U}}^{\prime}$ with a complement of its support defined by :

$\mathrm{B}_{\mathrm{U}}^{\prime}(\mathrm{y})=0 \Leftrightarrow \mathrm{T}^{*}(\sigma \mid \mathrm{B}(\mathrm{y}))=0 \Leftrightarrow \mathrm{B}(\mathrm{y})=0$ 
and a core defined by :

$\mathrm{B}_{\mathrm{U}}^{\prime}(\mathrm{y})=1 \Leftrightarrow \mathrm{T}^{*}(\sigma \mid \mathrm{B}(\mathrm{y}))=1 \Leftrightarrow \sigma \leq \mathrm{B}(\mathrm{y})$

We recognize the support and the core of a fuzzy set obtained from B through a modifier such as "approximately " [Bouchon-Meunier 87], with a parameter $1 / \sigma$ :

$\forall \mathrm{y} \in \mathrm{Y} \quad \mathrm{B}_{\mathrm{U}}^{\prime}(\mathrm{y})=\min (1, \mathrm{~B}(\mathrm{y}) / \sigma)$.

Equation (17) yields a conclusion $\mathrm{B}_{\mathrm{L}}^{\prime}$ with a complement of the support defined by : $\mathrm{B}_{\mathrm{L}}^{\prime}(\mathrm{y})=0 \Leftrightarrow \mathrm{T}^{*}(\sigma, \mathrm{B}(\mathrm{y}))=0 \Leftrightarrow \mathrm{B}(\mathrm{y})=0$

and a maximum value of the membership defined by :

$\sup _{\mathrm{y} \in \mathrm{Y}} \mathrm{B}_{\mathrm{L}}^{\prime}(\mathrm{y})=\sup _{\mathrm{y} \in \mathrm{Y}} \mathrm{T}(\sigma, \mathrm{B}(\mathrm{y}))=\sigma$

We can interpret $B_{L}^{\prime}$ as $m(B)$, for a restrictive modifier m such as "very".

We represent the upper and lower bounds of the conclusion, for instance in the case of the product triangular norm $\mathrm{T}(\mathrm{x}, \mathrm{y})=\mathrm{xy}$ in Figure 5, where $\mathrm{B}_{\mathrm{U}}^{\prime}$ is exactly defined by (18) and $\mathrm{B}_{\mathrm{L}}^{\prime}$ by the following membership function :

$\forall \mathrm{y} \in \mathrm{Y} \quad \mathrm{B}_{\mathrm{L}}^{\prime}(\mathrm{y})=\sigma \mathrm{B}(\mathrm{y})$

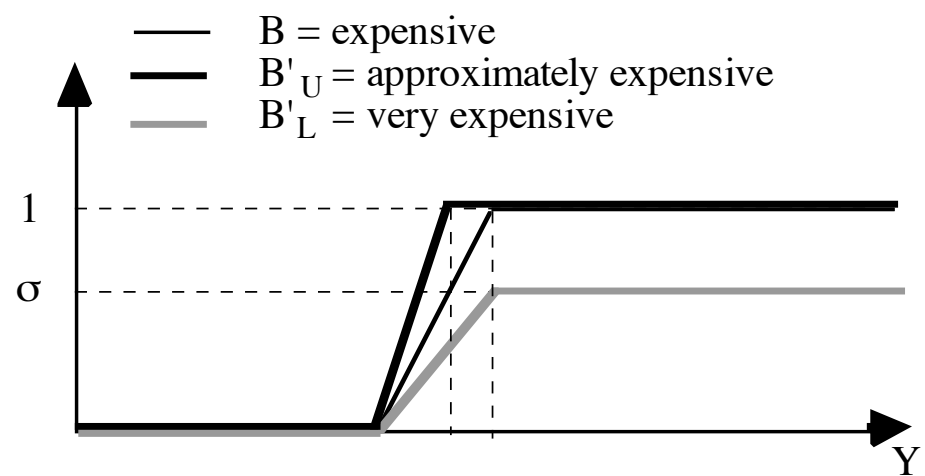

Figure 5 : Bounds of the conclusion with the product t-norm $\mathrm{T}$

\subsubsection{Case of non-strict triangular norms}

In this case, equation (16) yields a conclusion $\mathrm{B}_{\mathrm{U}}^{\prime}$ with a minimum value of membership function defined by $\mathrm{T}^{*}(\sigma \mid 0)$ since

$\forall \mathrm{y} \in \mathrm{Y} \quad \mathrm{B}_{\mathrm{U}}^{\prime}(\mathrm{y})=\mathrm{T}^{*}(\sigma \mid \mathrm{B}(\mathrm{y})) \geq \mathrm{T}^{*}(\sigma \mid 0)$,

because of $\mathrm{T}^{*}(\mathrm{x} \mid \mathrm{z})$ being non-decreasing in $\mathrm{z}$, and a core defined by :

$\mathrm{B}_{\mathrm{U}}^{\prime}(\mathrm{y})=1 \Leftrightarrow \mathrm{T}^{*}(\sigma \mid \mathrm{B}(\mathrm{y}))=1 \Leftrightarrow \sigma \leq \mathrm{B}(\mathrm{y})$

We recognize the support and the minimum of a fuzzy set $\mathrm{B}_{\mathrm{U}}^{\prime}$ obtained from $\mathrm{B}$ through a modifier such as "about" [Bouchon-Meunier 87], defined by a parameter $\mathrm{T}^{*}(\sigma \mid 0)$ and an uncertainty also equal to $\mathrm{T}^{*}(\sigma \mid 0)$, with membership function :

$\forall \mathrm{y} \in \mathrm{Y} \quad \mathrm{B}_{\mathrm{U}}^{\prime}(\mathrm{y})=\min \left(1, \max \left(0, \mathrm{~B}(\mathrm{y})+\mathrm{T}^{*}(\sigma \mid 0)\right)\right.$. 
Equation (17) yields a conclusion with a complement of the support of $\mathrm{B}_{\mathrm{L}}^{\prime}$ defined by :

$\mathrm{B}_{\mathrm{L}}^{\prime}(\mathrm{y})=0 \Leftrightarrow \mathrm{T}^{*}(\sigma, \mathrm{B}(\mathrm{y}))=0 \Rightarrow \mathrm{B}(\mathrm{y})=0$,

which proves that the support of $\mathrm{B}_{\mathrm{L}}^{\prime}$ may be strictly included in the support of $\mathrm{B}$, and the maximum value of the membership is equal to $\sigma$, like in 4.5.1. We can interpret $\mathrm{B}_{\mathrm{L}}^{\prime}$ as $\mathrm{m}(\mathrm{B})$, for a restrictive modifier such as "really".

In the case of Lukasiewicz triangular norm (4) for instance, we obtain a representation of $\mathrm{B}_{\mathrm{U}}^{\prime}$ by means of (20) and a representation of $\mathrm{B}_{\mathrm{L}}^{\prime}$ as follows :

$\forall \mathrm{y} \in \mathrm{Y} \quad \mathrm{B}_{\mathrm{L}}^{\prime}(\mathrm{y})=\max (0, \mathrm{~B}(\mathrm{y})-(1-\sigma))$

described in in Figure 6.

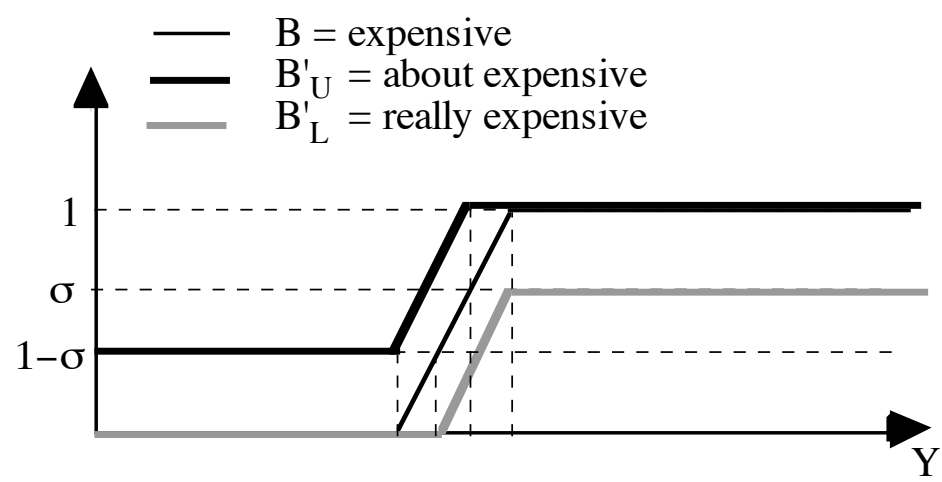

Figure 6 : Bounds of the conclusion with the Lukasiewicz t-norm T

We check that, if we choose also the Lukasiewicz triangular norm as a generalized modus ponens $t$ in (7), the results we have obtained in cases (C1) to (C4) with the two fuzzy implications (9) and (10) are compatible with these formal results and the conclusions $\mathrm{B}^{\prime}$ we have obtained are included between the two bounds $\mathrm{B}_{\mathrm{U}}^{\prime}$ and $\mathrm{B}_{\mathrm{L}}^{\prime}$ or, more precisely, between $\mathrm{B}_{\mathrm{U}}^{\prime}$ and $\mathrm{B}$. This is due to the fact that the compositional rule of inference provides conclusions $\mathrm{B}^{\prime}$ which are equal to $\mathrm{B}$ or which include $\mathrm{B}$. It is impossible to obtain $\mathrm{B}^{\prime}$ included in $\mathrm{B}$. Consequently, the formal definition of an analogical scheme by means of (AR1) and (AR2) allows more flexibility in the results of analogical reasoning than the strict utilization of resemblance relations and the heuristic definitions given in (12) and (13), mainly because of the symmetry appearing in (AR2).

\section{Conclusion}

We have given a formal definition of the concept of resemblance underlying any form of analogical reasoning. We have proven that resemblance relations can be used to define a kind of analogical scheme compatible with approximate reasoning in fuzzy 
logic, when we choose certain fuzzy implications for the compositional rule of inference. We have presented a less restrictive analogical scheme also based on resemblance relations. In both cases, we have given a constructive definition of the modification which must be applied to the conclusion $\mathrm{Ba}_{\mathrm{a}}$, solution of $\mathrm{A}_{\mathrm{a}_{0}}$, with the notations introduced in section 1 , to provide a solution $B^{\prime}$ to a new situation $A^{\prime}$. We have also shown that resemblance relations are not the only measures of comparison available for the representation of similarities in the framework of approximate reasoning and that other so-called measures of satisfiability are compatible with the compositional rule of inference defined by means of several other fuzzy implications.

\section{Acknowledgements}

The authors express their thanks to the reviewers and to Christophe Marsala for their valuable suggestions.

\section{References}

Baldwin J. (1979) A new approach to approximate reasoning using fuzzy logic, Fuzzy Sets and Systems 2, pp. 309-325.

Bouchon-Meunier B. (1987) Stability of linguistic modifiers compatible with a fuzzy logic, in Uncertainty and Intelligent Systems, Lecture Notes in Computer Science vol 313 (B. Bouchon, L. Saitta, R.R. Yager, eds.), pp. 63-70.

Bouchon-Meunier B. (1990) How to replace computations by simple rules in the framework of fuzzy logic, Proceedings COGNITIVA, AFCET, Madrid.

Bouchon-Meunier B. (1992) Logique floue et analyse des similitudes. Rapport LAFORIA 92/10

Bouchon-Meunier B. (1993) Fuzzy similitude and approximate reasoning, in Advances in Fuzzy Theory and Technology (P.P. Wang, ed.), pp.161-166

Bouchon-Meunier B., J. Delechamp, C. Marsala, M. Rifqi (1997), Several forms of fuzzy analogical reasoning, International Conference FUZZ-IEEE, Barcelona.

Bouchon-Meunier B., L. Valverde (1992) Fuzzy relations and analogy, Proceedings International Conference IPMU'92, Palma de Mallorca, Spain

Bouchon-Meunier B., L. Valverde (1993a) Analogy relations and inference, Proceedings 2nd IEEE International Conference on Fuzzy Systems, San Francisco, pp. $1140-1144$

Bouchon-Meunier B., L. Valverde (1993b) Analogical Reasoning and Fuzzy Resemblance, in Uncertainty in Intelligent Systems (B. Bouchon-Meunier, L. Valverde, R.R. Yager, eds.), Elsevier Science Pub, pp 247-255. 
Bouchon-Meunier B., L. Valverde (1996) A resemblance approach to analogical reasoning functions, in Fuzzy Logic in Artificial Intelligence (T.P. Martin, A.L. Ralescu, eds.), Springer Verlag, 1996, pp. 266-272.

Dubois D., H. Prade (1992). Fuzzy rules in knowledge-based systems -Modelling gradeness, uncertainty and preference, in An introduction to fuzzy logic applications in intelligent systems, (R.R. Yager, L.A. Zadeh, eds.) Kluwer Academic Publishers.

Magrez P., P. Smets (1989) Fuzzy modus ponens : a new model suitable for applications in knowledge-based systems, Int. J. Intelligent Systems, 4, pp. 181-200.

Mukaidono M., L. Ding, Shen Z. (1990) Approximate reasoning based on revision principle, Proc. NAFIPS, Toronto.

Richard J.F. (1995) Les activités mentales, comprendre, raisonner, trouver des solutions, Armand Colin.

Schweizer B., A. Sklar (1963) Associative functions and abstract semigroups, Publications Lathelaticae Debrecen 10, pp. 69-81

Smets P. (1991) Implication and modus ponens in fuzzy logic, in Conditional logic in expert systems, I.R. Goodman, M.M. Gupta, Nguyen H.T., G.S. Rogers (eds), Elsevier, pp. 235-268.

Turksen I.B., C. Lucas (1991) A pattern matching inference method and its comparison with known inference methods, Proc. IFSA World Congress, Brussels.

Turksen I.B., Zhao Zhong (1988) An approximate analogical reasoning approach based on similarity measures, IEEE Trans. Systems, Man and Cybernetics 18, pp. 10491056.

Valverde L. (1985) On the structure of F-indistinguishability operators, Fuzzy Sets and Systems 17, pp. 313-328

Zadeh L.A. (1971) Similarity relations and fuzzy orderings, Inform. Sci. pp. 177-200.

Zadeh L.A. (1979) A theory of approximate reasoning, in Machine Intelligence vol. 9, J. Hayes, D. Michie, L.I. Mikulich (eds.), Halstead Press, New York, pp. 149-194.

Zadeh L.A. (1983) The role of fuzzy logic in the management of uncertainty in Expert Systems, Fuzzy Sets and Systems 11, pp. 199-227. 